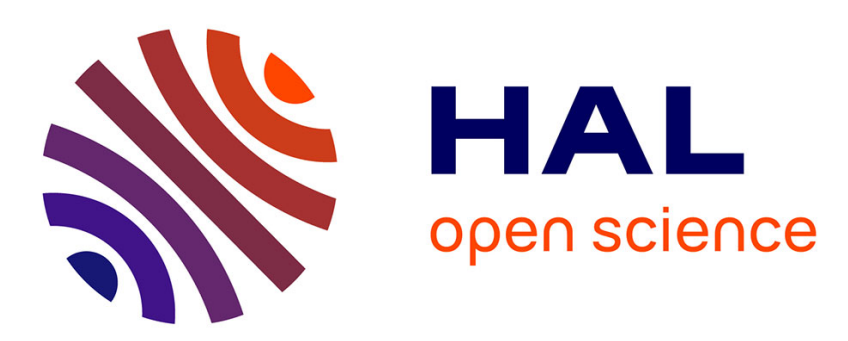

\title{
Photostability of D- -A nonlinear optical chromophores containing a benzothiazolium acceptor
}

Marek Cigáň, Anton Gáplovský, Ivica Sigmundová, Pavol Zahradník, Roman Dědic, Magdaléna Hromadová

\section{> To cite this version:}

Marek Cigáň, Anton Gáplovský, Ivica Sigmundová, Pavol Zahradník, Roman Dědic, et al.. Photostability of D- -A nonlinear optical chromophores containing a benzothiazolium acceptor. Journal of Physical Organic Chemistry, 2010, 24 (6), pp.450. 10.1002/poc.1782 . hal-00599808

\section{HAL Id: hal-00599808 https://hal.science/hal-00599808}

Submitted on 11 Jun 2011

HAL is a multi-disciplinary open access archive for the deposit and dissemination of scientific research documents, whether they are published or not. The documents may come from teaching and research institutions in France or abroad, or from public or private research centers.
L'archive ouverte pluridisciplinaire HAL, est destinée au dépôt et à la diffusion de documents scientifiques de niveau recherche, publiés ou non, émanant des établissements d'enseignement et de recherche français ou étrangers, des laboratoires publics ou privés. 


\section{Journal of Physical Organic Chemistry}

WILEY

\section{Photostability of D- $\pi$-A nonlinear optical chromophores containing a benzothiazolium acceptor}

\begin{tabular}{|r|l|}
\hline Journal: & Journal of Physical Organic Chemistry \\
\hline Manuscript ID: & POC-10-0140.R3 \\
\hline Wiley - Manuscript type: & Research Article \\
\hline Date Submitted by the & Au-Jun-2010 \\
\hline Complete List of Authors: & $\begin{array}{l}\text { Cigáň, Marek; Faculty of Natural Sciences, Comenius University, } \\
\text { Institute of Chemistry } \\
\text { Gáplovský, Anton; Faculty of Natural Sciences, Comenius } \\
\text { University, Institute of Chemistry } \\
\text { Sigmundová, Ivica; Faculty of Natural Sciences, Comenius } \\
\text { University, Department of Organic Chemistry } \\
\text { Zahradník, Pavol; Faculty of Natural Sciences, Comenius University, } \\
\text { Department of Organic Chemistry } \\
\text { Dědic, Roman; Faculty of Mathematics and Physics, Charles } \\
\text { University Prague, Department of Chemical Physics and Optics } \\
\text { Hromadová, Magdaléna; J. Heyrovský Institute of Physical } \\
\text { Chemistry of ASCR, v.v.i, Department of Molecular Electrochemistry }\end{array}$ \\
\hline Keywords: & $\begin{array}{l}\text { Photostability, benzothiazolium D- } \pi \text {-A NLO chromophores, Trans-cis } \\
\text { photoisomerization, Photooxidation, Singlet oxygen }\end{array}$ \\
\hline \hline
\end{tabular}

\section{s scholaroNE" \\ Manuscript Central}


Photostability of $D-\pi$-A nonlinear optical chromophores containing a benzothiazolium acceptor

Marek Cigáñ ${ }^{\mathrm{a}, *}$, Anton Gáplovskýa ${ }^{\mathrm{a}}$ Ivica Sigmundováa, Pavol Zahradník ${ }^{\mathrm{b}}$, Roman Dědic ${ }^{\mathrm{c}}$, Magdaléna Hromadovád

a Institute of Chemistry, Faculty of Natural Sciences, Comenius University, SK-842 15 Bratislava, Slovakia

${ }^{\mathrm{b}}$ Department of Organic Chemistry, Faculty of Natural Sciences, Comenius University, SK-842 15 Bratislava, Slovakia ${ }^{\mathrm{c} D e p a r t m e n t}$ of Chemical Physics and Optics, Faculty of Mathematics and Physics, Charles University Prague, CZ-12116 Prague, Czech Republic

${ }^{\mathrm{d}}$ Department of Molecular Electrochemistry, J. Heyrovsky Institute of Physical Chemistry of ASCR, v.v.i, CZ-182 23 Prague, Czech Republic

\begin{abstract}
For the practical application of second-order NLO materials, not only a high molecular quadratic hyperpolarizability $\beta$ but also good thermal, chemical and photochemical stabilities are required. Most of the state-of-the-art chromophores with high NLO response cannot be put to use because they are photochemically highly unstable. Good thermal and photochemical stabilities with preserved high hyperpolarizabilities can be achieved by replacement of an aromatic ring with easily delocalizable heteroaromatics, e.g. with benzothiazole. Furthermore, desirable modifications of the benzothiazole fragment lead to improvement in $\beta$ values. Here we report results of a comprehensive investigation of the photochemical stability of seven $D$ - $\pi$ - $A$ push-pull molecules based on a $N$-methylbenzothiazolium acceptor and a $N, N$-dimethylaminophenyl donor with a different length of conjugated bridge and different acceptor strength. The quantum yield $(\Phi)$ and the kinetic parameters of photoreactions were determined for existing photodegradation pathways on irradiation at $300-850 \mathrm{~nm}$ in $\mathrm{MeOH}$. Trans-cis photoisomerization is proposed as a fast but inefficient photobleaching mechanism for these irradiation wavelengths. Self-sensitized photooxidation by ${ }^{1} \mathrm{O}_{2}$ makes very slow parallel photodegradation pathway and, albeit to small value of $\Phi$, plays a dominant role in the photodegradation of the compounds investigated. Both structural modifications (extension of conjugated bridge and an additional acceptor group bonded
\end{abstract}


to heterocycle) resulting in an increase of NLO response led to a decrease in photostability due to the self-sensitized ${ }^{1} \mathrm{O}_{2}$ photooxidative attack. Thus a compromise should be found between an increase in NLO response and a decrease in photostability to make a choice of studied compounds for practical applications.

Keywords: Photostability, benzothiazolium $D-\pi-A$ NLO chromophores, Trans-cis photoisomerization, Photooxidation, Singlet oxygen.

*Corresponding author. Tel.: +421-2-60296306; Fax: +421-2-60296342; E-mail address: cigan@fns.uniba.sk (M. Cigáň)

\section{INTRODUCTION}

In the past fifteen years, a considerable effort has been focused on the development of organic molecules with enhanced second order nonlinear optical (NLO) properties due to their potential applications in various areas such as optical modulation, frequency doubling and molecular switching ${ }^{[1-5]}$. The most widely studied second-order (quadratic) NLO effects such as second harmonic generation (SHG) arise from high first molecular hyperpolarizabilities $\beta$. The most common design of molecules with large $\beta$ values comprises strong electron-donors and acceptors connected by a $\pi$-conjugated system (donor- $\pi$-acceptor or " push- pull', chromophores) ${ }^{[1,2]}$. In such donor- $\pi$-acceptor $(D-\pi$ - $A$ ) systems, the donor and acceptor moieties provide the necessity of ground-state charge asymmetry, whereas the $\pi$-conjugated bridge provides a pathway for the redistribution of electron density under the influence of external electric fields ${ }^{[6]}$.

For the practical application of second-order NLO materials, not only a high molecular quadratic hyperpolarizability $\beta$, but also good thermal, chemical and photochemical stabilities are required ${ }^{[7,8]}$. Good thermal and photochemical stabilities of NLO chromophores with preserved high hyperpolarizabilities can be achieved by replacement of an aromatic ring with easily delocalizable heteroaromatics ${ }^{[9]}$. In respect of these findings, benzothiazole-derived dyes with a $D-\pi$ - $A$ setup were promising candidates for NLO applications ${ }^{[10]}$. Further improvement in $\beta$ values was achieved by proper introduction of donor and acceptor substituents onto the benzothiazole core due to its nonsymmetric character and quaternization of the benzothiazole 
nitrogen ${ }^{[11]}$. Benzothiazolium styryl dye and its derivatives with different donors and acceptors were widely investigated in last century as good laser ${ }^{[12]}$ and NLO dyes ${ }^{[13]}$. Over the last few years, our research group synthesized a large number of push-pull 3-alkyl-benzothiazolium salts with different number $n$ of ethenylene units in a $\pi$-conjugated bridge and various donor and acceptor substituents ${ }^{[11,14-17]}$. The benzothiazolium salts were found to be much more effective NLO-phores in comparison with the corresponding neutral benzothiazoles. It was shown that the length of the $\pi$-conjugated bridge between the electron-donating group and benzothiazolium moiety, as well as the donor and acceptor ability, have a significant influence on $\beta$. Recently, Coe et al. ${ }^{[18]}$ reported the results of Hyper-Rayleigh scattering (HRS) measurements for 3-methylbenzothiazolium salts ( $n=1-4 ; D=N, N$-dimethylaminophenyl) in comparison with the analogous 1-methylpyridinium salts. Experimental measurements revealed that the static molecular quadratic hyperpolarizability $\beta_{0}$ increases with the length of polyene chain, and the benzothiazolium salts exhibit larger NLO responses than their pyridinium analogues.

In most cases, donors and acceptors in $D-\pi-A$ systems are connected via the conjugated bridge containing $\mathrm{C}=\mathrm{C}$ bonds. However, this bond readily undergoes trans-cis photoisomerization, which may hamper the material efficiency and lifetime. It was previously reported that the primary causes of photochemical instability of NLO chromophores containing $\mathrm{C}=\mathrm{C}$ bonds are photooxidation and photoisomerization ${ }^{[19-24]}$. In either case, the nonlinear activity is significantly diminished, the charge-transfer (CT) system is reduced, and new absorption features appear elsewhere in the spectrum, usually at a much shorter wavelength. The identity and the number of specific reactions and their relative rates are influenced in a complicated way by the exact identity of the chromophore, the influence of atmospheric environment, the irradiation wavelength, the temperature, etc. Photostability of organic dyes is consequently often considered the Achilles Heel of organic photonic materials ${ }^{[8,20,25,26]}$ and limits their practical applications. Most of the state-of-the-art chromophores which were designed to have high electro-optic coefficients and hyperpolarizabilities cannot be put to use because they are highly unstable and degrade because of a photochemically generated singlet oxygen ${ }^{[8,27]}$.

Here we report results of a comprehensive investigation of the photochemical stability, particularly the photooxidative stability of seven benzothiazolium iodides with a different length of conjugated bridge and a different acceptor strength of benzothiazolium core caused by withdrawing substituents. The studied compounds 1-7 are dipolar push-pull chromophores 
containing an $\mathrm{N}$-methylbenzothiazolium electron-acceptor group, an alkenylene conjugation spacer with 1-3 double bonds and an $N, N$-dimethylamino group as a donor in the para position of the substituted phenyl group. The acceptor strength of 4-7 is enhanced by introducing an additional withdrawing substituent into the benzothiazole fragment $\left(\mathrm{NO}_{2}\right.$ or $\left.\mathrm{CN}\right)$. The chemical structure of the compounds studied is presented in Fig. 1.

Experiments were carried out to determine the role of photoisomerization and photooxidation in the photodegradation of 1-7 and to evaluate the overall stability and availability of such molecules for practical applications.

\section{EXPERIMENTAL}

\section{Synthesis}

The compounds under study have been prepared by the condensation reactions as is presented in Fig. S1 (Supplementary Material) and has been published in [11]. The pyridine or piperidine have been used as the base. All compounds have all-trans configuration of double bonds in the conjugated bridge.

\section{Experimental techniques}

Electronic absorption spectra were obtained on a Hewlett Packard HP 8452A diode array spectrophotometer and fluorescence measurements were performed on a Hitachi F-2000 fluorescence spectrophotometer. The solvent used in all measurements was methanol $(\mathrm{MeOH})$ because of the good solubility of the compounds investigated and the good photostability of 2,5dimethylfuran (2,5-DMF) and 2,5-diphenylisobenzofurane (DPIBF) as actinometric indicators of photooxidative attack of singlet oxygen $\left({ }^{1} \mathrm{O}_{2}\right)$ in this solvent (Sections 2 and 3 in EXPERIMENTAL). All photodegradation measurements were carried out at $25^{\circ} \mathrm{C}$ in the dark with only the $100-\mathrm{W}$ xenon lamp as the light source. Concentrations of 1-7 never exceeded $2 \times 10^{-}$ ${ }^{5} \mathrm{~mol} \mathrm{dm}^{-3}$, to avoid molecule aggregation and photochemical dimerization processes.

\section{Photodegradation measurements}

All photochemical measurements were performed using the apparatus described elsewhere (Fig.7. without ultrasonic horn $\mathrm{H})^{[28]}$. The light source was a 100-W xenon lamp (300-850 nm; 
$\left.I_{0}=2.05 \pm 0.05 \times 10^{-5} \mathrm{~mol} \mathrm{~s}^{-1} \mathrm{dm}^{-3}\right)$. The actual concentration of compounds studied in air-saturated solutions during irradiation was measured spectrophotometrically (HP 8452A) at shielding the incident photon flux from the light source. Absorbed photon flux $I_{\mathrm{a}}$ (by compound $\mathrm{X}$ ) was calculated from emission curves for the light source measured on an Ocean Optics SD 2000 spectrophotometer using the following equation:

$$
I_{\mathrm{a}}=I_{0}-I_{\mathrm{T}}=I_{0} \int_{0}^{\infty}\left(1-10^{-\sum_{\mathrm{i}} A_{\lambda \mathrm{i}}}\right) \frac{A_{\lambda \mathrm{x}}}{\sum_{\mathrm{i}} A_{\lambda \mathrm{i}}} \frac{I_{\lambda}}{\int_{0}^{\infty} I_{\lambda} \mathrm{d} \lambda} \mathrm{d} \lambda=I_{0} \frac{\int_{\lambda} S_{0} \mathrm{~d} \lambda-\int_{\lambda} S_{\mathrm{T}} \mathrm{d} \lambda}{\int_{\lambda} S_{0} \mathrm{~d} \lambda},
$$

where $\int S_{0} \mathrm{~d} \lambda$ and $\int S_{\mathrm{T}} \mathrm{d} \lambda$ denote the total area under the emission spectrum of the light source after passing through a cuvette without and with $\mathrm{X}$, respectively, $I_{0}$ and $I_{\mathrm{T}}$ the incident and the transmitted photon flux, respectively, $A$ means absorbance (the value of absorbed photon flux during photodegradation depends on time - for detailed calculation of $\Phi$ during photodegradation of studied compounds using time-dependent values of $I_{\mathrm{a}}$ see eqns. (7) and (10)). The incident photon flux $I_{0}$ in all measurements was determined using the integrated form of the equation for $\Phi^{1} \mathrm{O}_{2}$ determination for a solution of a sensitizer with known $\Phi^{1} \mathrm{O}_{2}$ and an acceptor with known $\beta$ (eqn.(5)).

\section{Determination of singlet oxygen quenching rate constants $\left(k_{\mathbf{Q}}\right)$}

The rate constant $k_{\mathrm{Q}}$ for ${ }^{1} \mathrm{O}_{2}$ quenching (relative reactivity index $\beta_{\mathrm{Q}}=k_{\mathrm{d}} / k_{\mathrm{Q}}$; in this case $\beta_{\mathrm{Q}}$ includes both physical and chemical quenching) by 1-7 necessary for more accurate $\Phi^{1} \mathrm{O}_{2}$ determination were calculated based on inhibition of DPIBF oxidation $\left(\beta=1.1 \times 10^{-4} \mathrm{M}\right.$ in $\mathrm{MeOH}$ ${ }^{[29,30]}$ ) by competitive ${ }^{1} \mathrm{O}_{2}$ quenching ${ }^{[31,32]}$ using the following equations (in the primary model we replaced the concentrations with the corresponding absorbances):

$$
k_{\mathrm{Q}}=\frac{k_{\mathrm{r}}\left(\left[A_{\mathrm{DPIBF}} / \varepsilon_{\mathrm{DPIBF}}\right]_{\mathrm{t}}^{\mathrm{Q}}-\left[A_{\mathrm{DPIBF}} / \varepsilon_{\mathrm{DPIBF}}\right]_{\mathrm{t}}^{0}\right)+k_{\mathrm{d}} \ln \left(\left[A_{\mathrm{DPIBF}}\right]_{\mathrm{t}}^{\mathrm{Q}} /\left[A_{\mathrm{DPIBF}}\right]_{\mathrm{t}}^{0}\right)}{[\mathrm{Q}] \ln \left(\left[A_{\mathrm{DPIBF}}\right]_{0} /\left[A_{\mathrm{DPIBF}}\right]_{\mathrm{t}}^{\mathrm{Q}}\right)}
$$




$$
\text { or } \quad k_{\mathrm{Q}}=\frac{k_{\mathrm{d}}+k_{\mathrm{r}}[\mathrm{DPIBF}]_{0}}{[\mathrm{Q}]}\left[\frac{-\left(\frac{\mathrm{d}\left[A_{\mathrm{DPIBF}} / \varepsilon_{\mathrm{DPIBF}}\right]}{\mathrm{d} t}\right)^{0}}{\left(-\left(\frac{\mathrm{d}\left[A_{\mathrm{DPIBF}} / \varepsilon_{\mathrm{DPIBF}}\right]}{\mathrm{d} t}\right)^{\mathrm{Q}}\right)}-1\right] \text {, }
$$

and by monitoring the decrease of the DPIBF absorption band at different quencher concentration using Young's kinetic technique ${ }^{[33]}$ :

$$
S_{0} / S=1+k_{\mathrm{Q}} / k_{\mathrm{d}}[\mathrm{Q}]=1+1 / \beta_{\mathrm{Q}}[\mathrm{Q}] .
$$

Superscripts 0 and $\mathrm{Q}$ denote the absence and presence of quencher $\mathrm{Q},[\mathrm{DPIBF}]_{0}$ is the initial concentration of DPIBF, [Q] is the quencher concentration and $S$ is the slope of the plot of a firstorder disappearance of DPIBF at a given [Q]. Both methods were used to eliminate errors for time-dependent absorption measurements. ${ }^{1} \mathrm{O}_{2}$ was generated by $\mathrm{MB}$ sensitization $\left(\Phi^{1} \mathrm{O}_{2(\mathrm{MB})}=0.50 \pm 0.01\right.$ in $\left.\mathrm{MeOH}^{[29,34]}\right)$.

\section{Determination of the quantum yield of singlet oxygen production $\left(\Phi^{1} \mathrm{O}_{2}\right)$}

Values of $\Phi^{1} \mathrm{O}_{2}$ were determined using an equation that describes the change in concentration $c_{\mathrm{A}}$

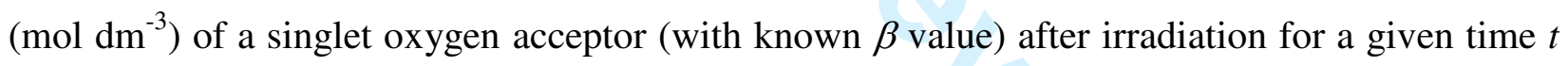
(s) in the presence of a singlet oxygen generator (sensitizer 1-7) that absorbs a photon flux $I_{\mathrm{a}}(\mathrm{mol}$ $\mathrm{s}^{-1} \mathrm{dm}^{-3}$ ) (Fig. 3) ${ }^{[34,35]}$ :

$$
\begin{gathered}
-\frac{\mathrm{d} c_{\mathrm{A}}}{\mathrm{d} t}=-\frac{\mathrm{d}[\mathrm{DMF}]}{\mathrm{d} t}=I_{\mathrm{a}} \Phi_{{ }_{\mathrm{O}_{2}(\mathrm{X})}} \frac{k_{\mathrm{DMF}}^{\mathrm{r}}[\mathrm{DMF}]}{k_{\mathrm{d}}+k_{\mathrm{DMF}}^{\mathrm{r}}[\mathrm{DMF}]+k_{\mathrm{Q}(\mathrm{X})}[\mathrm{X}]}=\frac{[\mathrm{DMF}]}{Z+[\mathrm{DMF}]}, \\
Z=\beta+\frac{k_{\mathrm{Q}(\mathrm{X})}[\mathrm{X}]}{k_{\mathrm{DMF}}^{\mathrm{r}}} .
\end{gathered}
$$

In this approach, we involved quenching of ${ }^{1} \mathrm{O}_{2}$ by a sensitizer using parameter $Z$. Parameter $Z$ is the sum of two components and includes overall (physical and chemical) 
quenching of ${ }^{1} \mathrm{O}_{2}$ by acceptor $\mathrm{A}\left(2,5-\mathrm{DMF} ; k_{\mathrm{r}}=3.9 .10^{8} \mathrm{dm}^{-3} \cdot \mathrm{mol}^{-1} \cdot \mathrm{s}^{-1}{ }^{[34]}\right)$ and sensitizer $\mathrm{X}$, and should be used for every sensitizer with high value of $k_{\mathrm{Q}}$ (e.g. omitting the parameter $Z$ for sensitizer 3 with high value of $k_{\mathrm{Q}}$ leads to a reduction in quantum yield of about $60 \%$ ). Parameter $\beta$ is the reactivity index of the acceptor (the ratio between the rate constants for nonradiative unimolecular decay of ${ }^{1} \mathrm{O}_{2}$ for the appropriate solvent $k_{\mathrm{d}}$ and acceptor oxidation $k_{\mathrm{r}}$ ) ${ }^{\text {[36] }}$. Its value represents the acceptor concentration at which half the reactive ${ }^{1} \mathrm{O}_{2}$ species will be trapped. Constant $k_{\mathrm{Q}}$ is the overall quenching constant for sensitizer X. Integrating the equation (5) and deducing acceptor concentrations from absorbance values gives:

$$
A_{\mathrm{a}}+\varepsilon_{\mathrm{DMF}} Z l \ln A_{\mathrm{a}}=A_{\mathrm{a} 0}+\varepsilon_{\mathrm{DMF}} Z l \ln A_{\mathrm{a} 0}-I_{\mathrm{a}} \varepsilon_{\mathrm{DMF}} l \Phi_{{ }_{1} \mathrm{O}_{2}(\mathrm{X})} t,
$$

where $A_{\mathrm{a} 0}$ and $A_{\mathrm{a}}$ are the acceptor absorbance (e.g. at the position of maximum absorption) before and at various irradiation times, $l$ is the optical path length $(\mathrm{cm})$ and $\varepsilon$ is the molar extinction coefficient of the acceptor. The slope of a plot of this equation against irradiation time gives $\Phi^{1} \mathrm{O}_{2}$ when the other parameters are known.

\section{Superoxide anion $\left(\mathrm{O}_{2}{ }^{-*}\right)$ detection by EPR}

Electron paramagnetic resonance (EPR) spectra were recorded on an ERS 230 instrument (ZWG Berlin, Germany), which operates in the X-band $(\sim 9.3 \mathrm{GHz})$ with a modulation amplitude of 0.1 $\mathrm{mT}$ and microwave power of $5 \mathrm{~mW}$. A sample containing $2.5 \times 10^{-5} \mathrm{~mol} \mathrm{dm}^{-3}$ of one of the derivatives studied was continuously irradiated at $\sim 60 \mathrm{~W} \mathrm{~m}^{-2}$ by a $250-\mathrm{W}$ halogen lamp through a $10-\mathrm{cm}$ water filter for $20 \mathrm{~min}$. The superoxide anion radical generated was indirectly monitored using a spin trap with 5,5-dimethyl-4,5dihydroxypyrrole- $N$-oxide (DMPO, Sigma; $c \sim 3.5 \times 10^{-4}$ $\left.\operatorname{mol~dm}{ }^{-3}\right)^{[37,38]}$.

\section{Phosphorescence measurements (determination of the energy of a triplet state $E_{\mathrm{T}}$ )}

Phosphorescence spectra were detected using a home-built set-up for detection of weak near-IR luminescence described in [39]. Excitation pulses of $\sim 10 \mu \mathrm{J}$ and $4.5 \mathrm{~ns}$ wide were provided by the dye laser Lambda Physik FL1000 pumped by the excimer laser ATL Lasertechnik ATLEX 500i. The excitation wavelengths and laser dyes were chosen to match different absorption spectra of the investigated molecules, namely 524nm (Coumarin 307), 540nm 
(Coumarin 153), and 575nm (Rhodamin 6G). The samples were excited through optically polished bottoms of fluorescence cells. Luminescence was collected by lens assembly through two long-pass filters Schott RG7 and high-luminosity monochromator Jobin Yvon H20IR to the infrared-sensitive photomultiplier Hamamatsu R5509 cooled to $-50{ }^{\circ} \mathrm{C}$ by liquid nitrogen. The pulses from the photomultiplier were fed through the Becker-Hickl HF AC-26dB preamplifier to the Becker-Hickl MSA 200 photon counter/multiscaler with time resolution of 5 ns per channel. The spectra were obtained as integrals of the counts in each of the kinetics at individual wavelengths in the spectral region from 750 to $1350 \mathrm{~nm}$ and corrected in respect to the spectral sensitivity of the detection set-up as well as to the equivalent absorbed energy. The kinetics were fitted by double exponential decays to obtain phosphorescence lifetimes.

\section{Determination of oxidation potential $\left(E^{0^{\prime}}\right)$}

Iodides 1-7 were metathesized to their corresponding hexafluorophosphate salts (due to interfering signal of $\mathrm{I}^{-}$anion) by precipitation from the $\mathrm{MeOH} / \mathrm{MeCN} /$ aqueous $\mathrm{KPF}_{6}$. Electrochemical measurements were done in a three-electrode arrangement using a home-made fast rise-time potentiostat. The instrument was interfaced to a personal computer via an IEEEinterface card (PC-Lab, AdvanTech Model PCL-848) and a data acquisition card (PCL-818) using 12-bit precision. Positive iR compensation just short of oscillations was used in all the measurements. The reference electrode $\mathrm{Ag} \mid \mathrm{AgCl} / 1 \mathrm{M} \mathrm{LiCl}$ was separated from the test solution by a salt bridge. The working electrode was a glassy carbon electrode with an area of $3.79 \times 10^{-3} \mathrm{~cm}^{2}$. The auxiliary electrode was a cylindrical platinum net. Ferrocene was used as an internal reference and all data are referred to the formal redox potential of the ferrocene/ferrocenium $\left(\mathrm{Fc} / \mathrm{Fc}^{+}\right)$couple equal to $+0.52 \mathrm{~V}$ in this system. Oxygen was removed from the solution by a stream of argon, which blanketed the solution throughout the measurements. $E^{0^{\prime}}$ values were obtained from the cyclic voltammetric measurements of $0.5 \mathrm{mM}$ solutions of 1-7 in acetonitrile and $0.1 \mathrm{M}$ tetrabutylammonium hexafluorophosphate supporting electrolyte. Error in the $E^{0^{\prime}}$ determination is $\pm 0.005 \mathrm{~V}$. Estimated values $E^{0^{\prime}}$ for $\mathbf{1 - 3}$ agree well with the literature data ${ }^{[18]}$. 


\section{RESULTS AND DISCUSSION}

\section{Spectral characteristics}

The UV-visible absorption spectra of salts 1-7 in $\mathrm{MeOH}$ were measured previously ${ }^{[11]}$. These spectra are dominated by intense low-energy bands in the visible region $\left(\lambda_{\mathrm{A}} 350-500 \mathrm{~nm}\right)$ attributable to $\pi \rightarrow \pi^{*}$ ICT transitions from the terminal electron-donating $N, N$-dimethyl groups to the central benzothiazolium skeleton. Less intense bands in the spectra are associated with nondirectional $\pi \rightarrow \pi^{*}$ transitions at higher energy. Basic absorption characteristics of ICT transitions (absorption maxima $\lambda_{\mathrm{A}}$, extinction coefficient $\log \varepsilon$, oscillator strength $f$, ICT energies $E_{\mathrm{A}}$ ) and calculated values of first hyperpolarizabilities $\beta$ (at the semiempirical PM3 level by the finite-field method) ${ }^{[11]}$ of benzothiazolium NLO chromophores 1-7 are presented in Table 1. ICT bands move predictably to lower energy with increasing conjugation length and with increasing acceptor strength of the benzothiazolium skeleton. An additional acceptor group bound to the benzothiazolium ring $\left(\mathrm{NO}_{2}\right.$ or $\left.\mathrm{CN}\right)$ has a controversial effect on the NLO response of 4-7. Addition of this group to chromophore 1 with single double bond enhances the value of $\beta$ and addition to chromophore 2 with two double bonds leads to a modest decrease in NLO response. A rising number of double bonds enhances the NLO response of benzothiazolium chromophores. The nonplanarity (decreasing conjugation strength) together with possible isomerisation in longer linkers ${ }^{[40]}$ could explain the lowered values of $\log \varepsilon$ and $f$ in absorption spectra of compound 6.

Fluorescence spectra showed very low intensity in $\mathrm{MeOH}$ (quantum yields of fluorescence $\Phi_{\mathrm{F}}$ never exceeded 0,005). This can be attributed to enhanced ICT interaction, which often results in fluorescence quenching due to enhanced probability of nonluminiscent ICT and TICT (twisted intramolecular charge transfer) state population in polar solvents ${ }^{[41]}$. The same effect was observed in a few push-pull $D$ - $\pi$-A salts and it has also a practical application ${ }^{[42]}$. The evidence of the final relaxed nonluminiscent dark TICT state in the commercial benzothiazolium push-pull laser dye LDS 751 (which is structurally very close to dye 2) was recently confirmed experimentally using the FS TR SEP FD method (femtosecond timeresolved stimulated emission pumping fluorescence depletion) ${ }^{[43]}$. Hydrogen bonding effect of the solvent can also contribute to the non-radiative internal conversion ${ }^{[41]}$.

Phosphorescence spectra were measured to estimate the energy of triplet states (the position of the main phosphorescence maxima $\lambda_{\mathrm{P}}$, Table 1) as one of the major factors that 
influence the production and quenching of singlet oxygen ${ }^{1} \mathrm{O}_{2}$ (RESULTS AND DISCUSSION Sections 2.2 and 2.3). All the studied compounds exhibit similar luminiscence spectra with $\lambda_{\mathrm{P}}$ around $852 \pm 11 \mathrm{~nm}$ and a shoulder around $910 \mathrm{~nm}$ as a consequence of the vibrational structure of the emissive state. Bathochromic shift of the main phosphorescence maximum with the length of the conjugated bridge was observed for chromophores 1-3. On the contrary, no such shift was found for compounds 4 and 6 and a hypsochromic shift was obtained for compounds 5 and 7. Luminescence intensity exhibits very strong dependence on the length of the conjugated bridge and on addition of the acceptor to $N$-methylbenzothiazolium moiety. It increases significantly with increasing length of the conjugated bridge. This effect was the most pronounced in chromophores 1-3, where compound 1 exhibited only approximately $3 \%$ of the total phosphorescence intensity of compound 2, while the phosphorescence intensity of compound 3 was $\sim 27$ times higher than that of compound 2. This effect was also observed in compounds 4 and 6 as well as in 5 and 7 where the total phosphorescence intensity increased 5 and 7 times, respectively, in the compounds with longer conjugated bridges. Time-resolved luminescence signals were accurately fitted by biexponential functions. We distinguished fast $\left(\tau_{1}\right)$ and slow $\left(\tau_{2}\right)$ decay times of approximately $80 \pm 10 \mathrm{~ns}$ and $1.3 \pm 0.1 \mu \mathrm{s}$, respectively, with the short component fractional yield of $\sim 70-75 \%$ from the biexponential fits. The short component of the luminiscence signal is assumed to result from a deactivation of the dark TICT state ${ }^{[43]}$ or it may be as well a component of phosphorescence. However, the second alternative is quite unusual for most organic triplets. All the respective lifetimes are quite similar, one can only say that longer component is always (for all different excitation wavelengths) slower in sample 3 (see Table 1). The striking differences in phosphorescence intensities of the different materials are therefore caused by different triplet state quantum yields and not by different quenching of the emitting states. Thus, the extension of the conjugated bridge and an additional acceptor group bonded to the heterocycle have a substantial effect on the triplet state population although they do not significantly influence the energy of the triplet states.

\section{Photostability}

As already mentioned, the NLO chromophores photostability is a very important characteristic with regard to their practical usage. There are two dominant processes leading to photodegradation of NLO chromophores containing a carbon-carbon double bond as part of a $\pi$ - 
conjugated bridge: trans-cis isomerization and photooxidation. To study the influence of the extension of the conjugated bridge and the addition of an acceptor group to the heterocycle on the photostability of 1-7, MeOH solutions of the compounds were subjected to irradiation with a 100W Xe lamp.

\section{Trans-cis photoisomerization}

Changes in the main absorption band (ICT transition) were monitored to determine the photodegradation quantum yield in air-saturated $\mathrm{MeOH}$ solutions under one-photon excitation at room temperature. Kinetic changes in the absorption spectra of 1-7 in $\mathrm{MeOH}$ on irradiation at 300-850 $\mathrm{nm}$ are presented in Figs. S2 (Supplementary Material) and 2. The main absorption during this irradiation corresponds to ICT transitions for all compounds studied. In all cases, the ICT absorption band initially decreased with irradiation time and the absorption bands were shifted to a shorter wavelength. After longer irradiation, a photostationary state was attained and the spectra of the reaction mixtures did not change with further irradiation (small concentration changes due to self-sensitized ${ }^{1} \mathrm{O}_{2}$ photooxidative attack were not detectable in such short time intervals). These results can be rationalized by the existence of trans-cis photoisomerization, leading to a photostationary state. The data was fitted to a monoexponential decay function and the decay rate constants determined from the fitted curves were used to calculate the quantum yield of photodegradation (i.e. photoisomerization) according to:

$$
\Phi_{\mathrm{deg}}=\frac{-\int_{c_{0}}^{c_{\mathrm{t}}} \mathrm{d} c}{\int_{0}^{t} I_{\mathrm{a}} \mathrm{d} t}=\frac{c_{0}-c_{\mathrm{t}}}{\frac{t_{0.9}}{\mathrm{n}+1} \sum_{i=0}^{n} \frac{I_{\mathrm{a}_{\mathrm{i}}}+I_{\mathrm{a}_{\mathrm{i}+1}}}{2}} \doteq \frac{c_{0}-c_{\mathrm{t}}}{\left(\frac{I_{\mathrm{a} 0}+I_{\mathrm{a} 0.9}}{2}\right) t_{0.9}}, \quad t_{0.9}=\frac{\ln 10}{k} .
$$

Values for the photodegradation rate constant $(k)$, the time for $50 \%$ degradation $\left(t_{0.5}\right)$, the time for $90 \%$ degradation $\left(t_{0.9}\right)$, the quantum yield for photodecomposition $\left(\Phi_{\mathrm{deg}}\right)$, the percent of initial isomer in the photostationary state and the contribution of self-sensitized photooxidation by ${ }^{1} \mathrm{O}_{2}$ to overall photodegradation during photoisomerization are summarized in Table 2. 
$\Phi_{\text {deg }}$ exhibited no concentration dependence, consistent with a first-order photodecomposition process. The values of $\Phi_{\text {deg }}$ ranged from $(0.11-0.14) \times 10^{-4}$ (2\% photodegradation) for 5 to (5.5$5.7) \times 10^{-4}(0.8 \%$ photodegradation $)$ for 2 , with the percentage photodegradation calculated from the asymptotes of the fitted exponential curves. Small values of $\Phi_{\mathrm{deg}}$ are most likely connected with the extent of CT character in the molecules studied. Substantial competition of the ICT (and/or TICT) excited-states population with the nonradiative phantom-state population (from the second one trans-cis isomerization occurs) and moreover the hydrogen bonding effect of $\mathrm{MeOH}$ may enhance the non-radiative internal conversion ${ }^{[41]}$. Addition of the third double bond to the conjugated bridge and an additional acceptor bound to position 6- of $N$-methylbenzothiazolium decreased the value of $\Phi_{\mathrm{deg}}$, although the overall percentage photodegradation slightly increased. Very rapid cis-trans photoisomerization of the initially formed cis isomer may be responsible for a low contribution of this pathway to the overall photodegradation. Trans-cis photoisomerization thus seems to be a fast (mainly for 1-3) but inefficient ( 1-7 \% decrease of initial concentration) photobleaching mechanism for these irradiation wavelengths. Contribution of self-sensitized photooxidation by ${ }^{1} \mathrm{O}_{2}$ (Section 2.4 in RESULTS AND DISCUSSION) as a parallel degradation pathway to the overall photodecomposition during trans-cis photoisomerization of 1-7 is not significant $(0-3 \%)$.

\section{Photooxidation}

There are two possible mechanisms for interaction between an excited dye molecule and dioxygen, which lead to the formation of singlet oxygen (Type II process) and a superoxide anion (Type I process), respectively, both of which can contribute to dye photofading ${ }^{[44,45]}$. Therefore, we conducted experiments to determine whether 1-7 generate these reactive oxygen species and whether there is evidence of self-sensitized photooxidation.

\subsection{Production of the superoxide anion radical $\mathrm{O}_{2}{ }^{--}$}

To study the generation of superoxide anion radical $\mathrm{O}_{2}^{--}$after photoexcitation of 1-7, EPR spintrapping was carried out with DMPO as the spin trapper ${ }^{[34,35]}$. After 20 min of irradiation with a 250-W halogen lamp only 4 showed a very low-intensity EPR signal (Fig. S3 in Supplementary Material) in the region of free radicals $(\mathrm{g}=2.004)$. This signal seemed to represent DMPO-O ${ }_{2}^{--}$ adduct with three coupling constants due to the nitrogen atom and two hydrogen atoms in the $\beta$ 
and $\gamma$ positions in this molecule $\left(\mathrm{A}_{\mathrm{N}}=13.3 \mathrm{G}, \mathrm{A}_{\mathrm{H}}{ }^{\alpha}=10.1 \mathrm{G}\right.$ and $\left.\mathrm{A}_{\mathrm{H}}{ }^{\beta}=1.5 \mathrm{G}\right)$. Experimental coupling constants agree well with literature data ${ }^{[37,38]}$. Electron transfer (formation of a superoxide anion radical) and subsequent oxidation reactions (followed by various radical recombinations) or nucleophilic addition of $\mathrm{O}_{2}{ }^{--}$thus may contribute to the overall degradation of 4.

\subsection{Production of singlet oxygen ${ }^{1} \mathrm{O}_{2}$}

Values for the quantum yield of singlet oxygen production $\left(\Phi^{1} \mathrm{O}_{2}\right)$ are summarized in Table 4 and outlined in Fig. 3. Relatively low values of $\Phi^{1} \mathrm{O}_{2}$ for all seven derivatives can be attributed to the ICT character of these molecules, which manifests its effect in sensitizer-oxygen contact complexes ${ }^{[46,47]}$. CT character in the sensitizer can influence the energy, yield, and lifetime of the triplet state, all of which can, likewise, ultimately be reflected in the singlet oxygen yield. Increasing CT interactions reduce the overall quantum yield of singlet oxygen formation $\Phi^{1} \mathrm{O}_{2}$ and the decrease is further enhanced in polar solvents due to the enhancement of CT interactions (stabilization of exciplexes of triplet excited sensitizer and $\mathrm{O}_{2}$ in moving from non-polar to highly polar solvents). The extent of CT, both within the sensitizer itself (i.e., intramolecular CT) as well as in the sensitizer-oxygen complex (i.e., intermolecular CT), thus have a large adverse effect on the efficiency with which singlet oxygen is generated ${ }^{[48]}$.

The increasing value of $\Phi^{1} \mathrm{O}_{2}$ after addition of the acceptor groups to the $N$ methylbenzothiazolium moiety of $\mathbf{1}$ (simultaneous increase of $E^{0^{\prime}}$ ) demonstrates an effect of intermolecular CT (molecules 4 and 5). This behavior does not take effect on going from molecule 2 to structure $\mathbf{6}$ and 7 and even a slight decrease of $\Phi^{1} \mathrm{O}_{2}$ in both cases was observed. These results suggest a controversial role of a combination of both inter- and intramolecular CT on the ${ }^{1} \mathrm{O}_{2}$ production efficiency, possibly affecting the quantum yield of the triplet state population and/or a triplet state deactivation pattern. As was previously mentioned by Nielsen et al. ${ }^{[48]}$, one cannot always rely on rule-of-thumb guidelines when attempting to construct either efficient or inefficient ${ }^{1} \mathrm{O}_{2}$ sensitizers and a full investigation of the photophysical properties of the system studied is generally required.

The value of $\Phi^{1} \mathrm{O}_{2}$ for 1-3 represents again an unexpected decrease of $\Phi^{1} \mathrm{O}_{2}$ of 1-3 with increasing value of $E_{0}$. This increasing tendency of a quantum yield with extension of conjugated 
bridge copies the ability of phosphorescence emission by molecules $\mathbf{1 - 3}$ although only qualitative conclusions of the emission probability could be done. This behavior is consistent with the fact that the $S_{0}-S_{1}$ excitation energy changes more with the conjugate chain length than that of $S_{0}-T_{1}$ ${ }^{[49,50]}$. Enhancement in rate constants for intersystem crossing for longer chains was observed and attributed to a lowering of the $S_{1}-T_{1}$ energy gap for longer chains ${ }^{[49,51]}$. Thus, molecules with longer conjugation lengths seem to have a higher triplet quantum yield. The first excited singlet states of 1-7 should not contribute markedly to overall ${ }^{1} \mathrm{O}_{2}$ production owing to their short lifetimes $\tau_{0} \leq 10 \mathrm{~ns}\left(\tau_{0}=1.5 / v_{\text {max }}^{2} f\right.$ where $v_{\max }$ is the wavenumber corresponding to the absorption maximum). The ${ }^{1} \mathrm{O}_{2}$ production efficiency of the studied molecules is clearly the greatest for $\mathbf{3}$ and the least for $\mathbf{1}$.

\subsection{Quenching of singlet oxygen}

Estimated values of ${ }^{1} \mathrm{O}_{2}$ quenching rate constants $k_{\mathrm{Q}}\left(\beta_{\mathrm{Q}}\right)$ (Table 3$)$ exceeded the values expected for an electronic-to-vibrational energy transfer (converting electronic excitation energy of the ${ }^{1} \mathrm{O}_{2}$ molecule into vibration of $\mathrm{O}_{2}$ and quencher Q) by orders of magnitude. These high values of $k_{\mathrm{Q}}$ regarding relatively high triplet energies $\left(E_{\mathrm{T}}>130 \mathrm{~kJ} \mathrm{~mol}^{-1}\right)$ and low oxidation potentials $\left(E^{0}<0.65 \mathrm{~V}\right)$ can be attributed to a CT-induced quenching of ${ }^{1} \mathrm{O}_{2}$, where the deactivation of the initially formed singlet encounter complex ${ }^{1}\left(\mathrm{Q}^{1} \Delta\right)_{\mathrm{EC}}$ is enhanced by the formation of a singlet exciplex ${ }^{1}\left(\mathrm{Q}^{1} \Delta\right)_{\mathrm{CT}}$, which is stabilized by the transfer of electric charge from the quencher to the oxygen molecule ${ }^{[52]}$. Iodides do not contribute significantly to such high $k_{\mathrm{Q}}$ values in protic solvents ${ }^{[53]}$. The formation of a singlet exciplex ${ }^{1}\left(\mathrm{Q}^{1} \Delta\right)_{\mathrm{CT}}$ is followed by isc to the ground-state CT complex, by chemical reaction, or by separation of free ions. Thus, the overall quenching rate constant $k_{\mathrm{Q}}$ can be additively composed of a physical and a chemical component, i.e., $k_{\mathrm{Q}}=k_{\mathrm{p}}+k_{\mathrm{r}}$.

$$
\mathrm{Q}+{ }^{1} \Delta \longleftrightarrow{ }^{1}\left(\mathrm{Q}^{1} \Delta\right)_{\mathrm{EC}} \longleftrightarrow{ }^{1}\left(\mathrm{Q}^{1} \Delta\right)_{\mathrm{CT}} \stackrel{k_{\mathrm{p}}}{\longrightarrow}{ }^{3}\left(\mathrm{Q}^{3} \Sigma\right)_{\mathrm{CT}} \longrightarrow \mathrm{Q}+{ }^{3} \Sigma
$$

Rate constants $k_{\mathrm{Q}}$ of 1-7 showed very strong dependence on the length of the conjugated bridge and an addition of acceptor group to the $N$-methylbenzothiazolium moiety. Values of $k_{\mathrm{Q}}$ increased significantly with both characteristics. Both quenching of ${ }^{1} \mathrm{O}_{2}$ and ${ }^{1} \mathrm{O}_{2}$ production depends on two main parameters: triplet-state energy $E_{\mathrm{T}}$ and oxidation potential of the sensitizer. The oxidation process is reversible for all studied compounds and its formal redox potential $E^{0^{\prime}}$ is 
reported in Table 3. Because of the almost constant value of $E_{\mathrm{T}}$, increasing $k_{\mathrm{Q}}$ with extension of the conjugated bridge can be rationalized by the decreasing value of $E^{0}$. This is an established phenomenon ${ }^{[52]}$. Albeit to the opposite effect of $\mathrm{NO}_{2}(\mathrm{CN})$ group addition on $E^{0^{\prime}}, k_{\mathrm{Q}}$ considerably increased after incorporation of these groups to the benzothiazolium moiety. Considering again the relatively constant values of $E_{\mathrm{T}}$, these results indicate a significant role of intramolecular charge-transfer (ICT) in the CT-induced quenching of ${ }^{1} \mathrm{O}_{2}$. ICT most likely plays an important role not only in the production of ${ }^{1} \mathrm{O}_{2}$, but also in the quenching of ${ }^{1} \mathrm{O}_{2}$. The increasing tendency of $k_{\mathrm{Q}}$ copies the increasing tendency of ground-state dipole moments $\mu^{[11]}$, although absolute correlation does not exist. Polarizability of the chromophore most likely contributes as another factor to CT-induced quenching of ${ }^{1} \mathrm{O}_{2}$. An opaque trend of $k_{\mathrm{Q}}$ behavior after the exchange of a $\mathrm{CN}$ group for an $\mathrm{NO}_{2}$ group in pairs 4-5 and 6-7 could be explained by different ground state geometry of compound 6 (values of $\log \varepsilon$ and $f$ in Table 1). Calculated $\mu$ of compound $\mathbf{6}$ probably do not correspond with an objective ground-state dipole moment.

\subsection{Self-sensitized photooxidation by ${ }^{1} \mathrm{O}_{2}$}

In many cases, CT quenching of ${ }^{1} \mathrm{O}_{2}$ additionally competes with chemical reactions, which are often far from negligible ${ }^{[52]}$. To determine the fraction of chemical reaction with ${ }^{1} \mathrm{O}_{2}$ in the overall quenching of ${ }^{1} \mathrm{O}_{2}$, we carried out a series of experiments in which the decrease in absorbance of 1-7 due to MB-generated ${ }^{1} \mathrm{O}_{2}$ in the absence of any other quencher was monitored. According to the mechanism of photooxidation by ${ }^{1} \mathrm{O}_{2}$, the reaction rate at low concentration $\left(\beta_{\mathrm{r}}>>[\mathrm{C}]\right)$ (assuming that $\left[{ }^{1} \mathrm{O}_{2}\right]$ is constant) is given by the following equations ${ }^{[33,34]}$ :

$$
-\frac{\mathrm{d}[\mathrm{C}]}{\mathrm{d} t}=\Phi_{\mathrm{r}} I_{\mathrm{a}}=\Phi_{\mathrm{a}_{2}(\mathrm{MB})} I_{\mathrm{a}} \frac{[\mathrm{C}]}{[\mathrm{C}]+\beta_{\mathrm{r}}}=k_{\mathrm{f}} \frac{[\mathrm{C}]}{[\mathrm{C}]+\beta_{\mathrm{r}}}=k_{\mathrm{f}} \frac{[\mathrm{C}]}{\beta_{\mathrm{r}}}=k_{\mathrm{f}} \frac{k_{\mathrm{r}}}{k_{\mathrm{d}}}[\mathrm{C}]=k_{\mathrm{r}}[\mathrm{C}]\left[1 \mathrm{O}_{2}\right]=K[\mathrm{C}]
$$

The photofading rate constant $K$ for the dyes was obtained from the slope of the plot

$$
\ln \left(A_{0} / A_{\mathrm{t}}\right)=K t
$$

where $K=[\mathrm{C}]\left[{ }^{1} \mathrm{O}_{2}\right]$.

Fig. 4 shows the photostability of 4-7 in $\mathrm{MeOH}$ against ${ }^{1} \mathrm{O}_{2}$ photooxigenative attack. The linear relationships between $\ln [\mathrm{C}]_{0} /[\mathrm{C}]_{\mathrm{t}}$ and $t$ indicate that these are first-order kinetics reactions. 
The slopes of the plots indicate that the photofading rate constant is the greatest for $\mathbf{4}$ and the smallest for 7 (Fig. 4B).

If the rate of ${ }^{1} \mathrm{O}_{2}$ formation $k_{\mathrm{f}}$ is known, then we can calculate an objective value of the secondorder rate constant $k_{\mathrm{r}}$ (or $\beta_{\mathrm{r}}$ ) for ${ }^{1} \mathrm{O}_{2}$ photooxidative attack. The $k_{\mathrm{f}}$ value was obtained by multiplying the known value $\Phi^{1} \mathrm{O}_{2}$ for $\mathrm{MB}$ in $\mathrm{MeOH}$ by the value of $I_{\mathrm{a}}$ absorbed by this sensitizer. Results are summarized in Table 3.

Concentrations of chromophores 1-3 did not change after 2 hours on irradiation at the same experimental conditions. This does not necessarily mean that molecules 1-3 do not react with ${ }^{1} \mathrm{O}_{2}$, but the second-order rate constant $k_{\mathrm{r}}$ should not exceed $10^{5} \mathrm{dm}^{3} \mathrm{~mol}^{-1} \mathrm{~s}^{-1}\left(\beta_{\mathrm{r}} \geq 0.1 \mathrm{~mol}\right.$ $\left.\mathrm{dm}^{-3}\right)$.

To determine the kinetic parameters of self-sensitized photooxidation due to ${ }^{1} \mathrm{O}_{2}$ production and subsequent reaction between ${ }^{1} \mathrm{O}_{2}$ and the sensitizer, we first calculated the timedependent concentration values $\left(c_{i+1}\right)$ for this photodegradation pathway using the following equations:

$$
c_{\mathrm{i}+1}=c_{\mathrm{i}} \exp ^{-\frac{\Phi_{\mathrm{O}_{2}} I_{\mathrm{ai}}}{\beta_{\mathrm{r}}} \Delta t}, \quad I_{\mathrm{ai}}=I_{\mathrm{a} 0} \frac{\left(1-10^{-\alpha c_{\mathrm{i}}}\right)}{\left(1-10^{-\alpha c_{0}}\right)} \quad \mathrm{i}=0,1,2, \ldots, \mathrm{n} ; \Delta t=50000 \mathrm{~s}
$$

and then subtracted the half-life times $\left(t_{1 / 2(1 \mathrm{O})}\right)$ of the self-sensitized photooxygenation reaction and the times of degradation of $90 \%$ of the compound $\left(t_{9 / 10(102)}\right)$ at these reaction from the corresponding graphs $c_{\mathrm{i}+1}=f\left(t_{\mathrm{i}}\right)$ (Fig. 5) (coefficients $\alpha$ were determined using OO SD 2000 spectrophotometer).

To compare the kinetic parameters of autooxidation by ${ }^{1} \mathrm{O}_{2}$ for molecules with (4-7) and without (1-3) an acceptor group bonded to the heterocycle, the maximum values of $k_{\mathrm{r}}=10^{5} \mathrm{dm}^{3}$ $\mathrm{mol}^{-1} \mathrm{~s}^{-1}\left(\beta_{\mathrm{r}} \geq 0.1 \mathrm{~mol} \mathrm{dm}^{-3}\right.$, respectively) for all three chromophores 1-3 was taken. Results are summarized in Table 4. The obtained order of self-sensitized photodegradation for 1-3 coincides with the order of photodegradation after 3 weeks of the exposure of solution of 1-3 $\left(10^{-4} \mathrm{~mol}^{-\mathrm{dm}^{-}}\right.$ ${ }^{3}$ ) to daily sunlight. For a more accurate estimation of kinetic parameters describing this 
degradation pathway for $\mathbf{1 - 3}$, further experiments with higher irradiation intensities and more effective sensitizer should be carried out.

The quantum yields $\left(\Phi_{\mathrm{r}(1 \mathrm{O} 2)}\right)$ of these self-sensitized photodegradations were calculated according to:

$$
\Phi_{\mathrm{r}(102)}=\frac{\Phi_{{ }_{1} \mathrm{O}_{2}}}{\beta_{\mathrm{r}}}[\mathrm{C}] .
$$

Values of $\Phi_{\mathrm{r}(1 \mathrm{O} 2)}$ are expressed as number $\times[\mathrm{C}]$ to point out their dependence on the concentration of the corresponding chromophore (Table 4). Times $t_{1 / 2(1 \mathrm{O} 2)}$ and $t_{9 / 10(1 \mathrm{O} 2)}$ are relatively high (except derivate 3 with $t_{1 / 2(1 \mathrm{O})} \sim 4$ days) and showed strong dependence on addition of an acceptor group to the heterocycle and the length of the conjugated bridge. Both structural changes decrease the overall photostability although the change is not so significant after the addition of an acceptor group to skeleton 2 . Self-sensitized photooxidation by ${ }^{1} \mathrm{O}_{2}$ thus makes a slow parallel degradation pathway for irradiation at $300-850 \mathrm{~nm}$ and, albeit to the small $\Phi$, contributes with large fraction to the overall photodegradation of 4-7 (and probably also of 1-3).

Exchange of the $\mathrm{NO}_{2}$ group for $\mathrm{CN}$ causes a large increase in the photostability of compound $\mathbf{5}$, but had only a very small influence on the photostability of 7 . This difference could be most likely due to the different ground state geometry of compound $\mathbf{6}$. The photostabilities of the chromophores can be placed in the order: $\mathbf{1}>\mathbf{5}>\mathbf{2}>\mathbf{7}>\mathbf{6}>\mathbf{4}>\mathbf{3}$. It is apparent that a compromise should be made between an increase in NLO response and a decrease in photostability to enable a choice of NLO chromophores for practical applications.

Finally, the minimal overall degradation $(\sim 1-2 \%)$ due to trans-cis photoisomerization, the relatively low quantum yield for self-sensitized photooxidation by ${ }^{1} \mathrm{O}_{2}$ as the main photodegradation pathway $(0.014 \times[\mathrm{C}]$ and $0.012 \times[\mathrm{C}])$ and the high $\beta$ values $\left(370 \times 10^{-30}\right.$ esu and $184 \times 10^{-30} \mathrm{esu}$ ) mean that compounds $\mathbf{2}$ and $\mathbf{5}$ are promising for NLO applications. Compound $\mathbf{3}$, albeit to very large value of $\beta$, is not a good candidate for practical NLO applications due to its poor photostability. 


\section{CONCLUSIONS}

In this paper, the photochemical stability of seven $D-\pi-A$ benzothiazolium salts as candidates for NLO chromophores were investigated. The studied compounds differed in length of conjugated bridge and presence (or absence) of an additional acceptor group $\left(\mathrm{NO}_{2}\right.$ or $\left.\mathrm{CN}\right)$ bound to position 6- of the $N$-methylbenzothiazolium moiety. The photoreaction quantum yield and the kinetic parameters were determined for existing photodegradation pathways on irradiation at 300-850 nm in $\mathrm{MeOH}$. The most rapid reaction for any of the seven substrates is trans-cis photoisomerization, which leads to a photostationary state and contributes with a low percent $(\sim 1-7 \%$ decrease of initial concentration) to the overall photodegradation. Photooxidation by ${ }^{1} \mathrm{O}_{2}$ gives a second very slow parallel degradation pathway and, albeit to small values of $\Phi$, plays a dominant role in the photodegradation of 1-7. Electron transfer (formation of a superoxide anion radical) and subsequent oxidation reactions (followed by various radical recombinations) or nucleophilic addition of $\mathrm{O}_{2}^{--}$may contribute to the overall degradation of compound 4. Both structural modifications increasing NLO response (extension of the conjugated bridge and an additional acceptor group bonded to the heterocycle) led to a decrease in photostability due to manifestation of the main photodegradation pathway (self-sensitized ${ }^{1} \mathrm{O}_{2}$ photooxidative attack). From the values of the kinetic parameters of self-sensitized photooxidation by ${ }^{1} \mathrm{O}_{2}$, it can be concluded that a compromise should be made between an increasing NLO response and a decreasing photostability to enable a choice of NLO chromophores 1-7 for practical applications. The existence of photostationary states at $\sim 1-2 \%$ degradation by photoisomerization and low photochemical quantum yield $(\Phi=0.014 \times[\mathrm{C}]$ and $0.012 \times[\mathrm{C}])$ for the main photodegradation pathway, together with high $\beta$ values mean that $\mathbf{2}$ and $\mathbf{5}$ are promising derivatives for NLO applications.

\section{Acknowledgements}

This work was supported by the Slovak Research and Development Agency through APVV Grant No. 0259-07, by the Slovak Grant Agency for Science (VEGA No. 1/ 0639/08), UK Grant No. UK/229/2007, Grant Agency of the Czech Republic (GACR 203/08/1157), and by the project MSM 0021620835 from the Ministry of Education, Youth, and Sports of the Czech Republic. 


\section{REFERENCES}

[1]H. S. Nalwa, S. Miyata, Nonlinear Optics of Organic Molecules and Polymers, CRC Press, New York, 1997.

[2]S.R. Marder, B. Kippelen, A.K.-Y. Jen, N. Peyghambarian, Nature 1997, 388, 845.

[3]Y. Shi, Ch. Zhang, H. Zhang, J.H. Bechtel, L.R. Dalton, B.H. Robinson, W.H. Steier, Science 2000, 288, 119.

[4]L.R. Dalton, Pure Appl. Chem. 2004, 76, 1421.

[5]L.R. Dalton, Thin Solid Films 2009, 518, 428.

[6]D.R. Kanis, M.A. Ratner, T.J. Marks, Chem. Rev. 1994, 94, 195.

[7]L.R. Dalton, Ch. Zhang, M.-Ch. Oh, H. Zhang, W.H. Steier, Chem. Mater. 2001, 13, 3043.

[8]B. Murali, M.B.J. Diemeer, A. Driessen, M. Faccini, W. Verboom, D.N. Reinhoudt, A. Borreman, M.J. Gilde, Proceedings Symposium IEEE/LEOS Benelux Chapter, 2004, Ghent.

[9]E.M. Breitung, Ch.-F. Shu, J.R. McMahon, J. Am. Chem. Soc. 2000, 122, 1154.

[10]P. Hrobárik, P. Zahradník, W.M.F. Fabian, Phys. Chem. Chem. Phys. 2004, 6, 495.

[11]I. Sigmundová, P. Zahradník, D. Loos, Collect. Czech. Chem. Commun. 2007, 72, 1069.

[12]M.H. Lu, Y.M. Liu, Appl. Phys. B 1992, 354, 288.

[13] G.J. Ashwell, P.D. Jackson, W.A. Crossland, Nature 1994, 368, 438

[14]M. Zajac, P. Hrobárik, P. Magdolen, P. Foltínová, P. Zahradník, Tetrahedron 2008, 64, 10605.

[15]P. Hrobárik, I. Sigmundová, P. Zahradník, Synthesis 2005, 600-604.

[16]R. Buffa, R.; P. Zahradník, P. Foltínová, Collect. Czech. Chem. Commun. 2002, 67, 1820.

[17]R. Buffa, R.; P. Zahradník, P. Foltínová, Heterocycl. Commun. 2001, 7, 331.

[18]B.J. Coe, J.A. Harris, J.J. Hall, B.S. Brunschwig, S.-T. Hung, W. Libaers, K. Clays, S.J. Coles, P.N. Horton, M.E. Light, M.B. Hursthouse, J. Garín, J. Orduna, Chem. Mater. 2006, 18, 5907.

[19]A. Galvan-Gonzalez, M. Canva, G.I. Stegeman, R. Twieg, K.P. Chan, T.C. Kowalczyk, X.Q. Zhang, H.S. Lackritz, S.Marder, S. Thayumanavan, Opt. Lett. 2000, 25, 332.

[20]A. Galvan-Gonzalez, K.D. Belfield, G.I. Stegeman, M. Canva, S.R. Marder, K. Staub, G. Levina, R.J. Twieg, J. Appl. Phys. 2003, 94, 756.

[21]A. Galvan-Gonzalez, M. Canva, G.I. Stegeman, Appl. Phys. Lett. 1999, 75, 3306.

[22]A. Galvan-Gonzalez, G.I. Stegeman, A.K.-Y. Jen, X. Wu, M. Canva, A.C. Kowalczyk, X.Q. Zhang, H.S. Lackritz, S. Marder, S. Thayumanavan, G. Levina, J. Opt. Soc. Am. B 2001, 18, 1846.

[23]M.E. DeRosa, M. He, J.S. Cites, S.M. Garner, Y.R. Tang, J. Phys. Chem. B 2004, 108, 8725.

[24]D. Rezzonico, M. Jazbinsek, P. Günter, Ch. Bosshard, D.H. Bale, Y. Liao, L.R. Dalton, P.J. Reid, J. Opt. Soc. Am. B 2007, 24, 2199.

[25]C.C. Corredor, K.D. Belfield, M.V. Bondar, O.V. Przhonska, S. Yao, J. Photochem. Photobiol. A: Chem. 2006, 184, 105.

[26]K.D. Belfield, M.V. Bondar, O.V. Przhonska, K.J. Schafer, J. Photochem. Photobiol. A: Chem. 2004, 162, 569.

[27]A. Abbotto, L. Beverina, G. Chirico, A. Facchetti, P. Ferruti, G.A. Pagani, Synth. Metals 2003, 139, 629.

[28]A. Gáplovský, Š. Toma, J. Donovalová, J. Photochem. Photobiol. A: Chem. 2007, 191, 162.

[29]K.D. Belfield, C.C. Corredor, A.R. Morales, M.A. Dessources, F.E. Hernandez, J. Fluorescence 2006, 16, 105.

[30]A.A. Krasnovsky Jr., Ya.V. Roumbal, A.V. Ivanov, R.V. Ambartzumian, Chem. Phys. Lett. 2006, 430, 260. 
[31]H. Shiozaki, H. Nakazumi, Y. Takamura, T. Kitao, Bull. Chem. Soc. Jpn. 1990, 63, 2653.

[32]B.M. Monroe, J. Phys. Chem. 1977, 81, 1861.

[33]P. Chen, S. Sun, Y. Hu, Z. Qian, D. Zheng, Dyes Pigm. 1999, 41, 227.

[34]F. Wilkinson, W.P. Helman, A.B. Ross, J. Phys. Chem. Ref. Data 1995, 24, 663.

[35]F. Amat-Guerri, M.M.C. López-González, R. Martínez-Utrilla, J. Photochem. Photobiol. A: Chem. 1990, 53, 199.

[36]Y. Usui, M. Tsukada, H. Nakamura, Bull. Chem. Soc. Jpn. 1978, 51, 379.

[37]K.J. Reszka, M. Takayama, R.H. Sik, C.F. Chignell, Isao Saito, Photochem. Photobiol. 2005, $81,573$.

[38]S. Wei, J. Zhou, D. Huang, X. Wang, B. Zhang, J. Shen, Dyes Pigm. 2006, 71, 61.

[39]R. Dědic, A. Svoboda, J. Pšenčík, J. Hála, J. Mol. Struct. 2003, 301, 651.

[40]M. Dekhtyar, W. Rettig, M. Sczepan, Phys. Chem. Chem. Phys. 2000, 2, 1129.

[41]S.E.-D.H. Etaiw, T.A. Fayed, N.Z. Saleh, J. Photochem. Photobiol. A: Chem. 2006, 177, 238.

[42]W. Rettig, W. Baumann, in Progress in Photochemistry and Photophysics, Volume VI, (Ed: J.F. Rabek) CRC Press Inc., Boca Raton, Florida, 1992, 100.

[43]X. Guo, S. Wang, A. Xia, H. Su, J. Phys. Chem. A 2007, 111, 5800.

[44]S.N. Batchelor, D. Carr, C.E. Coleman, L. Fairclough, A. Jarvis, Dyes Pigm. 2003, 59, 269.

[45]X. Chen, X. Peng, A. Cui, B. Wang, L. Wang, R. Zhang, J. Photochem. Photobiol. A: Chem. 2006, 181,79 .

[46]C.B. Nielsen, M. Johnsen, J. Arnbjerg, M. Pittelkow, S.P. McIlroy, P.R. Ogilby, M. Jørgensen, J. Org. Chem. 2005, 70, 7065.

[47]S.P. McIlroy, E. Cló, L. Nikolajsen, P.K. Frederiksen, C.B. Nielsen, K.V. Mikkelsen, K.V. Gothelf, P.R. Ogilby, J. Org. Chem. 2005, 70, 1134.

[48]C.B. Nielsen, J. Arnbjerg, M. Johnsen, M. Jørgensen, P.R. Ogilby, J. Org. Chem. 2009, 74, 9094.

[49]M. Bennati, K. Németh, P.R. Surján, Mehring, M, J. Chem. Phys. 1996, 105, 4441.

[50]D. Beljonne, J. Cornil, R.H. Friend, R.A.J. Janssen, J.L. Brédas, J. Am. Chem. Soc. 1996, $118,6453$.

[51]E. Peeters, A.M. Ramos, S.C.J. Meskers, R.A.J. Janssen, J. Chem. Phys. 2000, 112, 9445.

[52]C. Schweitzer, R. Schmidt, Chem. Rev. 2003, 103, 1685.

[53]J.R. Kanofsky, P.D. Sima, Photochem. Photobiol. 2000, 71, 361. 


\section{Figure Legends}

Fig. 1. Chemical structure of the studied $D-\pi-A$ benzothiazolium salts.

Fig. 2. Changes in the concentrations of 1-3 (A) and 4-7 (B) in $\mathrm{MeOH}$ on irradiation with a 100W Xe lamp (300-850 nm; $\left.I_{0}=2.05 \pm 0.05 \times 10^{-5} \mathrm{~mol} \mathrm{~s}^{-1} \mathrm{dm}^{-3}\right)$. Time-dependent concentrations are fitted by single exponential functions [dotted line].

Fig. 3. Kinetic changes in the absorption spectra of 2,5-DMF in $\mathrm{MeOH}$ during irradiation of 2 (A) and 7 (B) at 300-850 nm $\left(I_{0}=2.05 \pm 0.05 \times 10^{-5} \mathrm{~mol} \mathrm{~s}^{-1} \mathrm{dm}^{-3}\right)$. Absorbed photon flux at $t=0 \mathrm{~s}$ was $I_{\mathrm{a} 0}=1.38 \times 10^{-5} \mathrm{~mol} \mathrm{~s}^{-1} \mathrm{dm}^{-3}$ for 2 and $I_{\mathrm{a} 0}=1.05 \times 10^{-5} \mathrm{~mol} \mathrm{~s}^{-1} \mathrm{dm}^{-3}$ for 7 .

Fig. 4. (A) Photodegradation of 4 in $\mathrm{MeOH}$ due to photooxidation by $\mathrm{MB}$-generated ${ }^{1} \mathrm{O}_{2}$ $\left(\Phi^{1} \mathrm{O}_{2}=0.50 \pm 0.01, I_{\mathrm{a}}=4.5 \pm 0.5 \times 10^{-6} \mathrm{~mol} \mathrm{~s}^{-1} \mathrm{dm}^{-3}\right.$ for $\mathrm{MB}$; colour filter with transmittance $>550$ $\mathrm{nm}$ was used to avoid direct photodegradation of 4). (B) Photostability of MeOH solutions of 4-7 against ${ }^{1} \mathrm{O}_{2}$ photooxidative attack (dotted lines - linear regression of experimental data).

Fig. 5. Calculated photodegradation curves of (A) 1-3 and (B) 4-7 in $\mathrm{MeOH}$ due to self-sensitized ${ }^{1} \mathrm{O}_{2}$ photooxidative attack during irradiation at $300-850 \mathrm{~nm}$ (incident photon flux $\mathrm{I}_{0}=2.05 \times 10^{-5}$ $\left.\mathrm{mol} \mathrm{s}^{-1} \mathrm{dm}^{-3}\right)$. 
Table 1. Photophysical properties of the molecules studied

\begin{tabular}{cccccccccc}
$\lambda_{\mathrm{A}}$ & $\begin{array}{c}E_{\mathrm{A}} \\
(\mathrm{kJ})\end{array}$ & $\log \varepsilon$ & $f$ & $\begin{array}{c}\lambda_{\mathrm{P}} \\
(\mathrm{nm})\end{array}$ & $\begin{array}{c}E_{\mathrm{T}} \\
\left(\mathrm{kJ} \mathrm{mol}^{-1}\right)\end{array}$ & $\begin{array}{c}\tau_{1} \\
(\mathrm{~ns})\end{array}$ & $\begin{array}{c}\tau_{2} \\
(\mu \mathrm{s})\end{array}$ & $\begin{array}{c}\beta \\
\left(10^{-30} \mathrm{esu}\right)\end{array}$ \\
\hline $\mathbf{1}$ & 520 & 230 & 4.83 & 1.07 & 841 & 142 & $85 \pm 3$ & $1.3 \pm 0.4$ & 98.5 \\
$\mathbf{2}$ & 562 & 213 & 4.78 & 1.24 & 851 & 141 & $76 \pm 4$ & $1.2 \pm 0.1$ & 370.1 \\
$\mathbf{3}$ & 580 & 206 & 4.75 & 1.33 & 861 & 139 & $79 \pm 8$ & $1.4 \pm 0.1$ & 744.8 \\
$\mathbf{4}$ & 562 & 213 & 4.90 & 0.99 & 854 & 140 & $82 \pm 9$ & $1.2 \pm 0.1$ & 183.3 \\
$\mathbf{5}$ & 551 & 217 & 4.91 & 1.01 & 863 & 139 & $90 \pm 8$ & $1.2 \pm 0.1$ & 183.7 \\
$\mathbf{6}$ & 630 & 190 & 4.54 & 0.53 & 852 & 140 & $83 \pm 1$ & $1.2 \pm 0.2$ & 317.3 \\
$\mathbf{7}$ & 618 & 194 & 4.83 & 1.14 & 850 & 142 & $83 \pm 2$ & $1.1 \pm 0.1$ & 321.0 \\
\hline
\end{tabular}

$\lambda_{\mathrm{A}}$ - the absorption maximum, $\log \varepsilon$ - the extinction coefficient, $f$ - the oscillator strength, $E_{\mathrm{A}}-$ the ICT energies, $\lambda_{\mathrm{P}}$ the phosphorescence maximum, $E_{\mathrm{T}}$ - the energy of triplet state, $\tau_{1}$ and $\tau_{2}$ - fast and slow decay time of luminescence signals, $\beta$ - the first hyperpolarizability 
Table 2. Photodegradation characteristics of 1-7 on irradiation at $300-850 \mathrm{~nm}$

\begin{tabular}{|ccccccc|} 
Dye & $\begin{array}{c}k \\
\left(10^{-4} \mathrm{~s}^{-1}\right)\end{array}$ & $\begin{array}{c}t_{0.5} \\
(\mathrm{~min})\end{array}$ & $\begin{array}{c}t_{0.9} \\
(\mathrm{~min})\end{array}$ & $\Phi_{\operatorname{deg}} \times 10^{-4}$ & $\%$ initial & $\begin{array}{c}\%{ }^{1} \mathrm{O}_{2} \\
\text { contribution }\end{array}$ \\
\hline $\mathbf{1}$ & 1800 & 0.07 & 0.22 & 4.33 & 99.6 & 0.002 \\
$\mathbf{2}$ & 1150 & 0.10 & 0.33 & 5.60 & 99.2 & 0.060 \\
$\mathbf{3}$ & 76.0 & 1.52 & 5.05 & 0.57 & 97.9 & 2.2 \\
$\mathbf{4}$ & 7.8 & 15 & 49 & 0.15 & 96.7 & 3.2 \\
$\mathbf{5}$ & 10.0 & 12 & 38 & 0.13 & 97.9 & 1.4 \\
$\mathbf{6}$ & 9.1 & 13 & 42 & 0.66 & 92.8 & 0.6 \\
$\mathbf{7}$ & 10.0 & 12 & 38 & 0.18 & 97.2 & 1.5 \\
\hline
\end{tabular}

$k$ - the photodegradation rate constant, $t_{0.5}$ - the time for $50 \%$ degradation, $t_{0.9}$ - the time for $90 \%$ degradation, $\Phi_{\text {deg }}$ the quantum yield for photodecomposition, $\%$ initial - the percent of initial isomer in the photostationary state, $\%{ }^{1} \mathrm{O}_{2}$ contribution - the contribution of self-sensitized photooxidation by ${ }^{1} \mathrm{O}_{2}$ to overall photodegradation during photoisomerization 
Table 3. Parameters for characterization of physical and chemical quenching of ${ }^{1} \mathrm{O}_{2}$ by 1-7

\begin{tabular}{|ccccccc|} 
Dye & $\begin{array}{c}k_{\mathrm{Q}} \\
\left(10^{9} \mathrm{dm}^{3} \mathrm{~mol}^{-1} \mathrm{~s}^{-1}\right)\end{array}$ & $\begin{array}{c}\beta_{\mathrm{Q}} \\
\left(10^{-5} \mathrm{~mol} \mathrm{dm}^{-3}\right)\end{array}$ & $\begin{array}{c}E^{0^{\prime}} \mathrm{vs} F c / F c^{+} \\
(\mathrm{V})\end{array}$ & $\begin{array}{c}\mu \\
(\mathrm{D})\end{array}$ & $\begin{array}{c}k_{\mathrm{r}} \\
\left(10^{6} \mathrm{dm}^{3} \mathrm{~mol}^{-1} \mathrm{~s}^{-1}\right)\end{array}$ & $\begin{array}{c}\beta_{\mathrm{r}} \\
\left(10^{-2} \mathrm{~mol} \mathrm{dm}^{-3}\right)\end{array}$ \\
\hline $\mathbf{1}$ & 0.17 & 65.0 & 0.567 & 2.4 & $\leq 0.1$ & $\geq 10$ \\
$\mathbf{2}$ & 1.50 & 7.3 & 0.381 & 4.1 & $\leq 0.1$ & $\geq 10$ \\
$\mathbf{3}$ & 5.00 & 2.2 & 0.264 & 7.3 & $\leq 0.1$ & $\geq 10$ \\
$\mathbf{4}$ & 1.20 & 9.2 & 0.626 & 12.4 & 3.2 & 3.5 \\
$\mathbf{5}$ & 0.41 & 26.8 & 0.610 & 7.3 & 1.5 & 7.5 \\
$\mathbf{6}$ & 3.70 & 3.0 & 0.435 & 12.0 & 2.2 & 5.0 \\
$\mathbf{7}$ & 7.10 & 1.6 & 0.424 & 6.1 & 1.5 & 7.3 \\
\hline
\end{tabular}

$k_{\mathrm{Q}}$ - the rate constant for overall ${ }^{1} \mathrm{O}_{2}$ quenching, $\beta_{\mathrm{Q}}$ - the relative reactivity index (includes both physical and chemical quenching) for ${ }^{1} \mathrm{O}_{2}$ quenching, $E^{0^{\prime}}$ - the formal redox potential, $\mu$ - the ground-state dipole moment, $k_{\mathrm{r}}$ - the rate constant for ${ }^{1} \mathrm{O}_{2}$ photooxidative attack, $\beta_{\mathrm{r}}$ - the reactivity index of dye with ${ }^{1} \mathrm{O}_{2}$ 


\begin{tabular}{|cccccc|}
\hline $\begin{array}{l}\text { Table 4. Parameters } \\
\text { photooxidation }\end{array}$ & for characterization of ${ }^{1} \mathrm{O}_{2}$ production by $\mathbf{1 - 7}$ and subsequent & self-sensitized \\
Dye & $\Phi^{1} \mathrm{O}_{2}$ & $\begin{array}{c}E^{0^{\prime}} \text { vs } F c / F c^{+} \\
(\mathrm{V})\end{array}$ & $\begin{array}{c}t_{1 / 2(1 \mathrm{O} 2)} \\
(\text { days })\end{array}$ & $\begin{array}{c}t_{9 / 10(1 \mathrm{O} 2)} \\
(\text { days })\end{array}$ & $\Phi_{\mathrm{r}(1 \mathrm{O} 2)}$ \\
\hline $\mathbf{1}$ & 0.0006 & 0.567 & 80.5 & 362 & $0.0063 \times[\mathrm{C}]$ \\
$\mathbf{2}$ & 0.0014 & 0.381 & 29.5 & 124 & $0.014 \times[\mathrm{C}]$ \\
$\mathbf{3}$ & 0.0098 & 0.264 & 4.1 & 15 & $0.098 \times[\mathrm{C}]$ \\
$\mathbf{4}$ & 0.0012 & 0.626 & 13.5 & 60 & $0.034 \times[\mathrm{C}]$ \\
$\mathbf{5}$ & 0.0009 & 0.610 & 38.8 & 177 & $0.012 \times[\mathrm{C}]$ \\
$\mathbf{6}$ & 0.0011 & 0.435 & 25.0 & 115 & $0.021 \times[\mathrm{C}]$ \\
$\mathbf{7}$ & 0.0012 & 0.424 & 27.0 & 116 & $0.017 \times[\mathrm{C}]$ \\
\hline
\end{tabular}

$\Phi^{1} \mathrm{O}_{2}$ - the quantum yield of ${ }^{1} \mathrm{O}_{2}$ production, $E^{0^{\prime}}$ - the formal redox potential, $t_{1 / 2(1 \mathrm{O} 2)}$ and $t_{9 / 10(1 \mathrm{O} 2)}-$ the halflife time of the self-sensitized photooxygenation reaction and the time of degradation of $90 \%$ of the compound at these reaction, $\Phi_{\mathrm{r}(1 \mathrm{O} 2)}$ - the quantum yield of the self-sensitized photodegradation by ${ }^{1} \mathrm{O}_{2}$ 


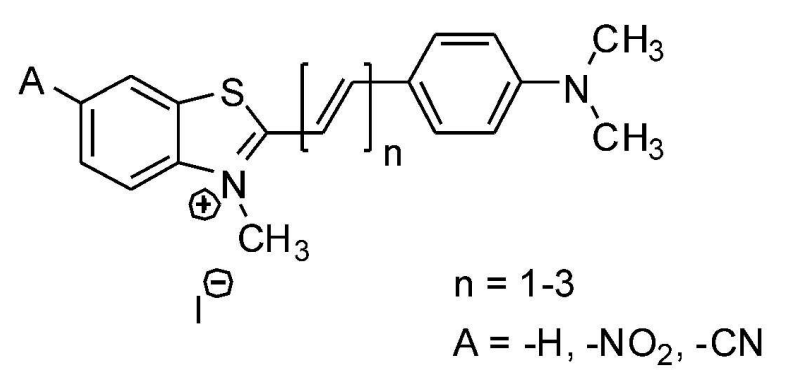

\begin{tabular}{ccc}
\hline Dye & $n$ & $A$ \\
\hline $\mathbf{1}$ & 1 & $-\mathrm{H}$ \\
$\mathbf{2}$ & 2 & $-\mathrm{H}$ \\
$\mathbf{3}$ & 3 & $-\mathrm{H}$ \\
$\mathbf{4}$ & 1 & $-\mathrm{NO}_{2}$ \\
$\mathbf{5}$ & 1 & $-\mathrm{CN}$ \\
$\mathbf{6}$ & 2 & $-\mathrm{NO}_{2}$ \\
$\mathbf{7}$ & 2 & $-\mathrm{CN}$ \\
\hline
\end{tabular}

Fig. 1. Chemical structure of the studied D- $\square$-A benzothiazolium salts. 

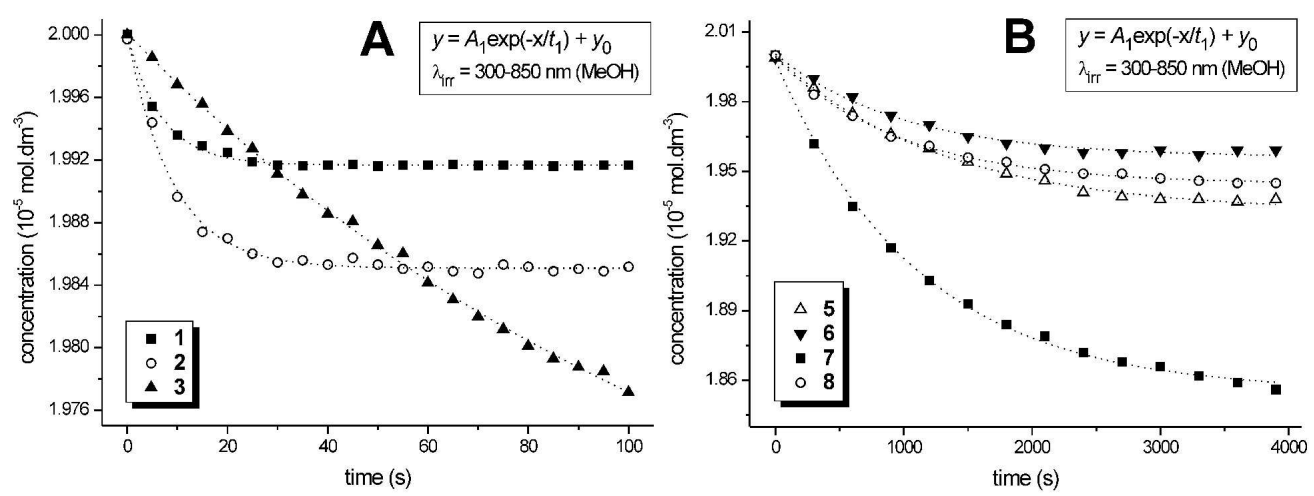

Fig. 2. Changes in the concentrations of 1-3 (A) and 4-7 (B) in $\mathrm{MeOH}$ on irradiation with a 100-W Xe lamp $(300-850 \mathrm{~nm} ; \mathrm{I} 0=2.05 \pm 0.05 \times 10-5 \mathrm{~mol} \mathrm{~s}-1 \mathrm{dm}-3)$. Time-dependent concentrations are fitted by single exponential functions [dotted line]. 

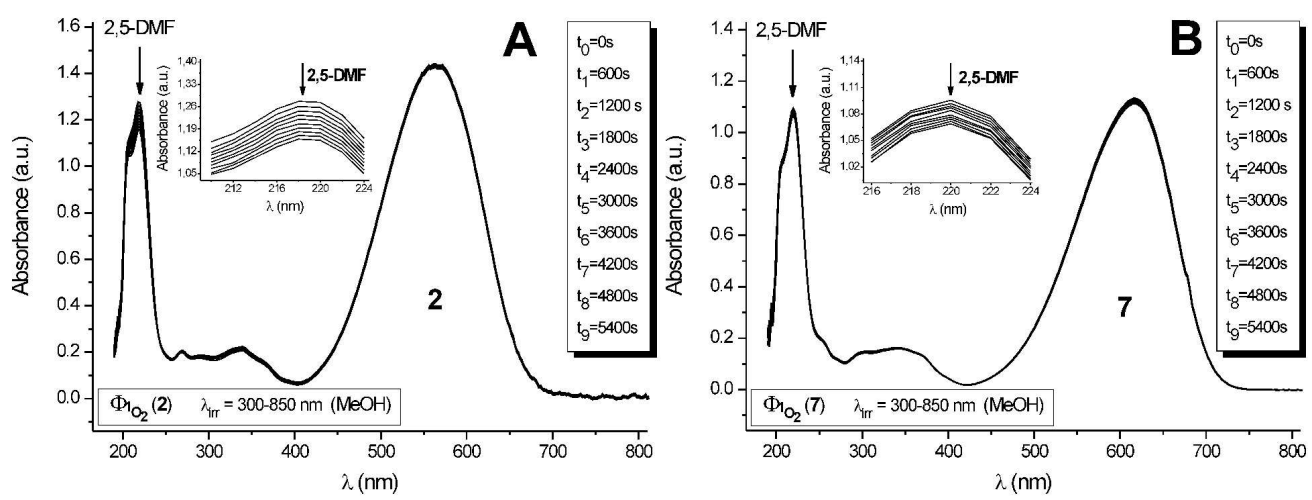

Fig. 3. Kinetic changes in the absorption spectra of 2,5-DMF in MeOH during irradiation of 2 (A) and 7 (B) at $300-850 \mathrm{~nm}(\mathrm{IO}=2.05 \pm 0.05 \times 10-5 \mathrm{~mol} \mathrm{~s}-1 \mathrm{dm}-3)$. Absorbed photon flux at $\mathrm{t}=0 \mathrm{~s}$ was $\mathrm{Ia} 0=1.38 \times 10-5 \mathrm{~mol} \mathrm{~s}-1 \mathrm{dm}-3$ for 2 and $\mathrm{Ia} 0=1.05 \times 10-5 \mathrm{~mol} \mathrm{~s}-1 \mathrm{dm}-3$ for 7 . 

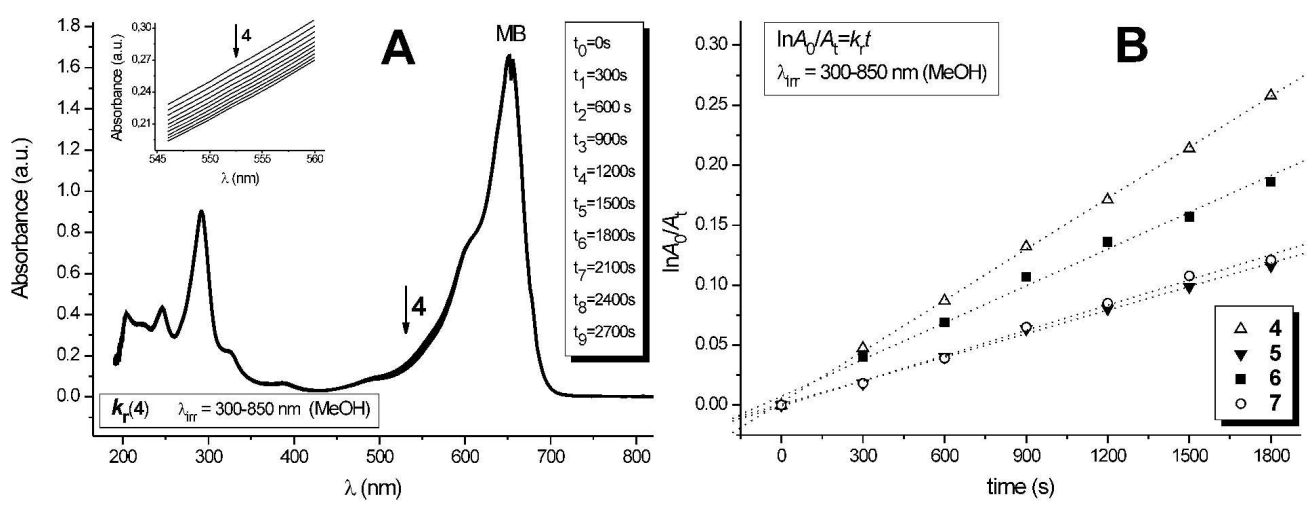

Fig. 4. (A) Photodegradation of 4 in $\mathrm{MeOH}$ due to photooxidation by MB-generated 102 $(\Phi 102=0.50 \pm 0.01, \mathrm{Ia}=4.5 \pm 0.5 \times 10-6 \mathrm{~mol} \mathrm{~s}-1 \mathrm{dm}-3$ for $\mathrm{MB}$; colour filter with transmittance $>550$ $\mathrm{nm}$ was used to avoid direct photodegradation of 4). (B) Photostability of MeOH solutions of 4-7 against 102 photooxidative attack (dotted lines - linear regression of experimental data). 

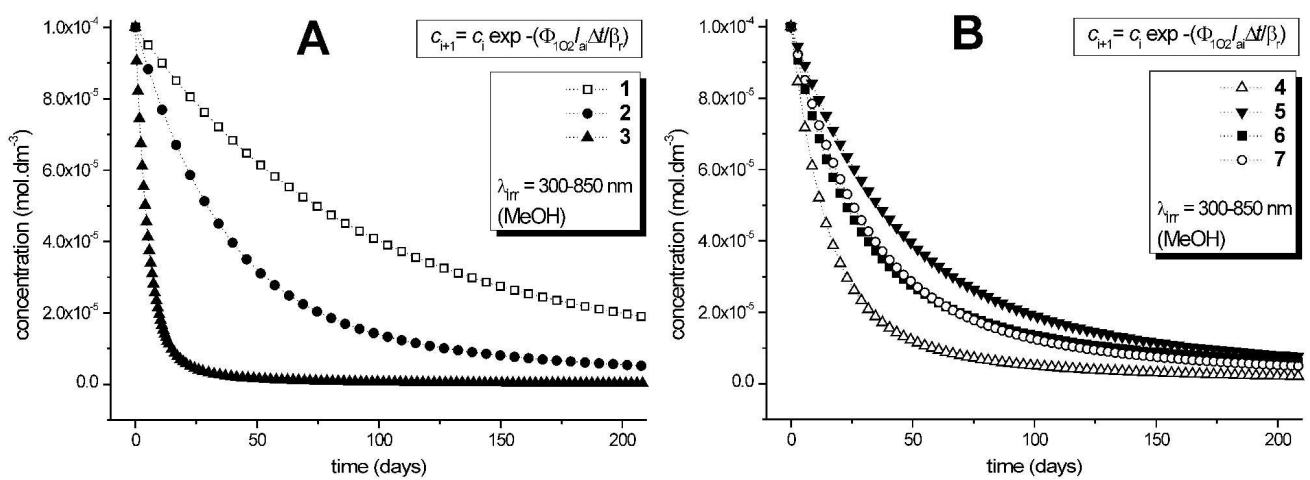

Fig. 5. Calculated photodegradation curves of (A) 1-3 and (B) 4-7 in $\mathrm{MeOH}$ due to self-sensitized 102 photooxidative attack during irradiation at $300-850 \mathrm{~nm}$ (incident photon flux $\mathrm{I} 0=2.05 \times 10-5 \mathrm{~mol}$ s-1 dm-3). 